\title{
Etherification of Wood-Based Hemicelluloses for
}

\section{Interfacial Activity}

Tiina Nypelö ${ }^{1}$, Christiane Laine ${ }^{2 *}$, Masaaki Aoki ${ }^{3}$, Tekla Tammelin ${ }^{2}$ and Ute Henniges ${ }^{1 *}$

1 University of Natural Resources and Life Sciences, Vienna, Konrad Lorenz Straße 24, 3430

Tulln

2 VTT Technical Research Centre of Finland Ltd., P.O. Box 1000, 02044 Espoo, Finland

3 Shinshu University, Faculty of Textile Science and Technology, 3-15-1 Tokida, Ueda,

Nagano, 386-8567, Japan

* Corresponding author emails, ute.henniges@boku.ac.at, christiane.laine@vtt.fi

\section{Differential scanning calorimetry (DSC)}

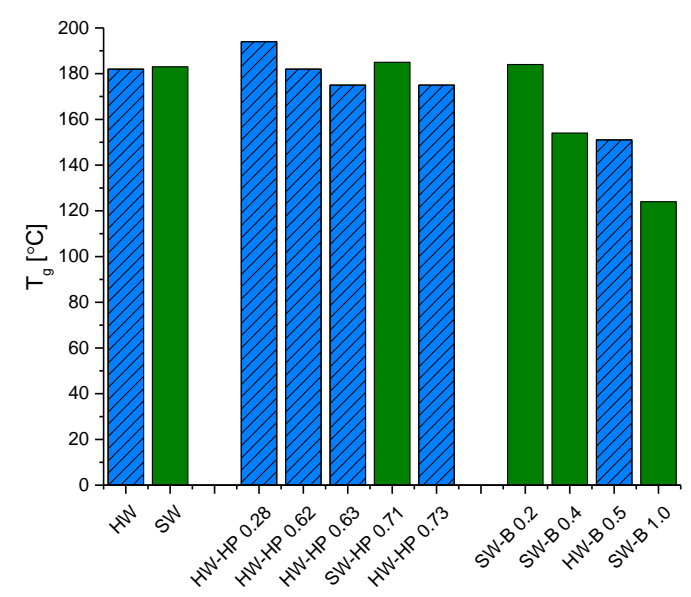

Figure S1. Glass transition temperature $\left(\mathrm{T}_{\mathrm{g}}\right.$ ) of the hydroxypropylated (DS 0.28-0.73) and butylated (DS 0.2-1.0) hemicelluloses as determined by differential scanning calorimetry. The hardwood (HW) and softwood (SW) grades are identified in blue (diagonal pattern) and green (no pattern) colors, respectively. 


\section{Infra-red (IR) analysis of hemicellulose ethers}

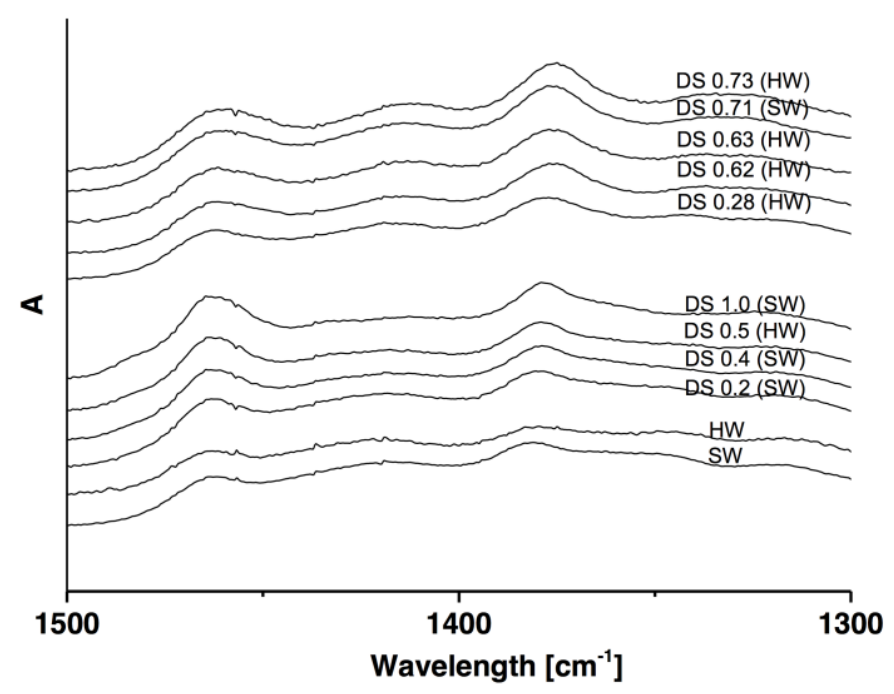

Figure S2. Attenuated total reflectance IR spectra of the hydroxypropylated and butylated hemicellulose grades at $1500-1300 \mathrm{~cm}^{-1}$.

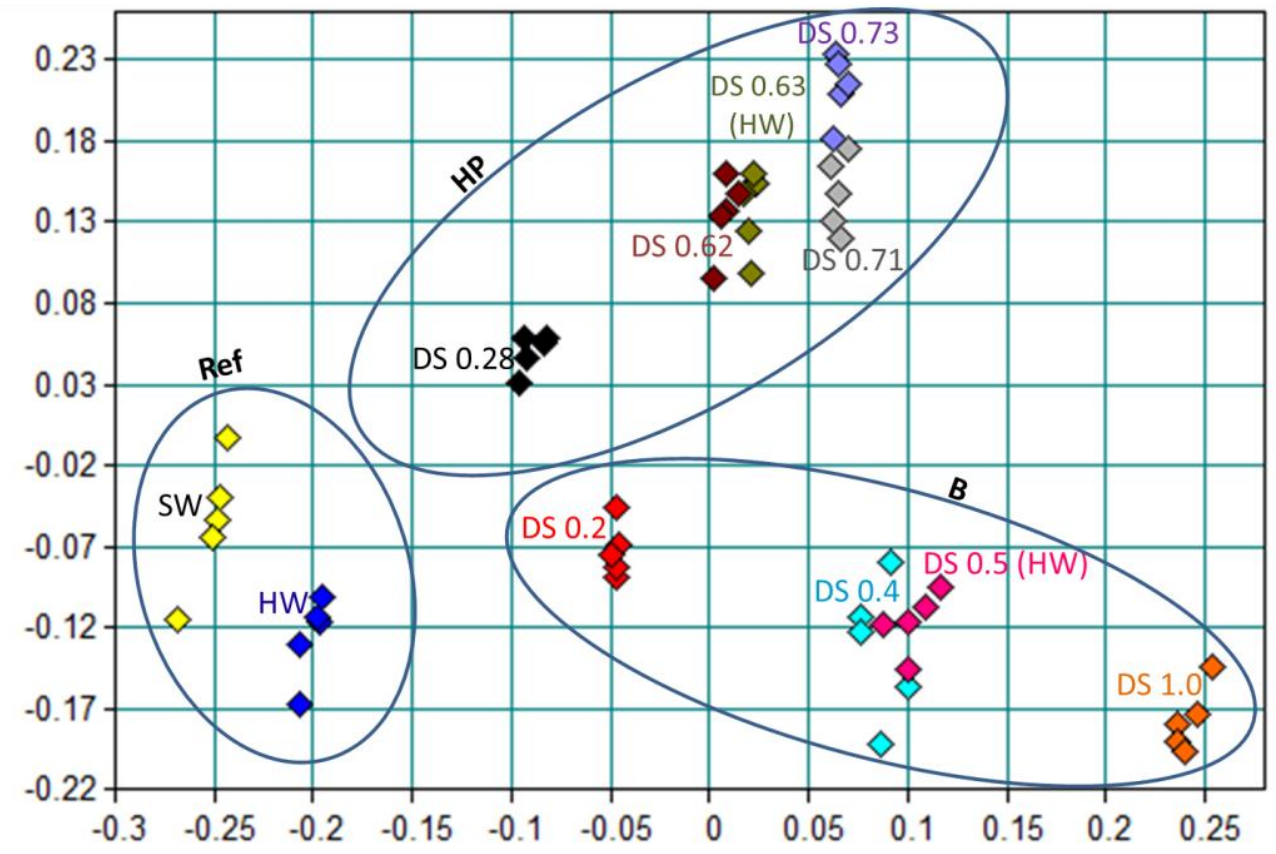

Figure S3. PCA-plot of the hydroxypropylated and butylated hemicellulose grades. Unless the grade is denoted within the parenthesis, hemicellulose was extracted from softwood. Each modified hemicellulose grade is noted by a color including the parallel analyses. 


\section{Molar mass determination}

The molar masses of the hemicellulose ethers were determined using GPC. The molar mass distributions (presented in the main article) are based on the elution profiles presented in Figure S4. The weight averaged molar masses derived from the measurements are presented in Table S1. However, since the $\mathrm{dn} / \mathrm{dc}$ of $0.136 \mathrm{ml} \mathrm{g}^{-1}$, that of cellulose, was used for the calculations, the molar masses are directive and the information that should be derived, rather than the exact values for the molar mass, are the changes (degradation/ increase) in the derivatives in comparison to the starting materials.
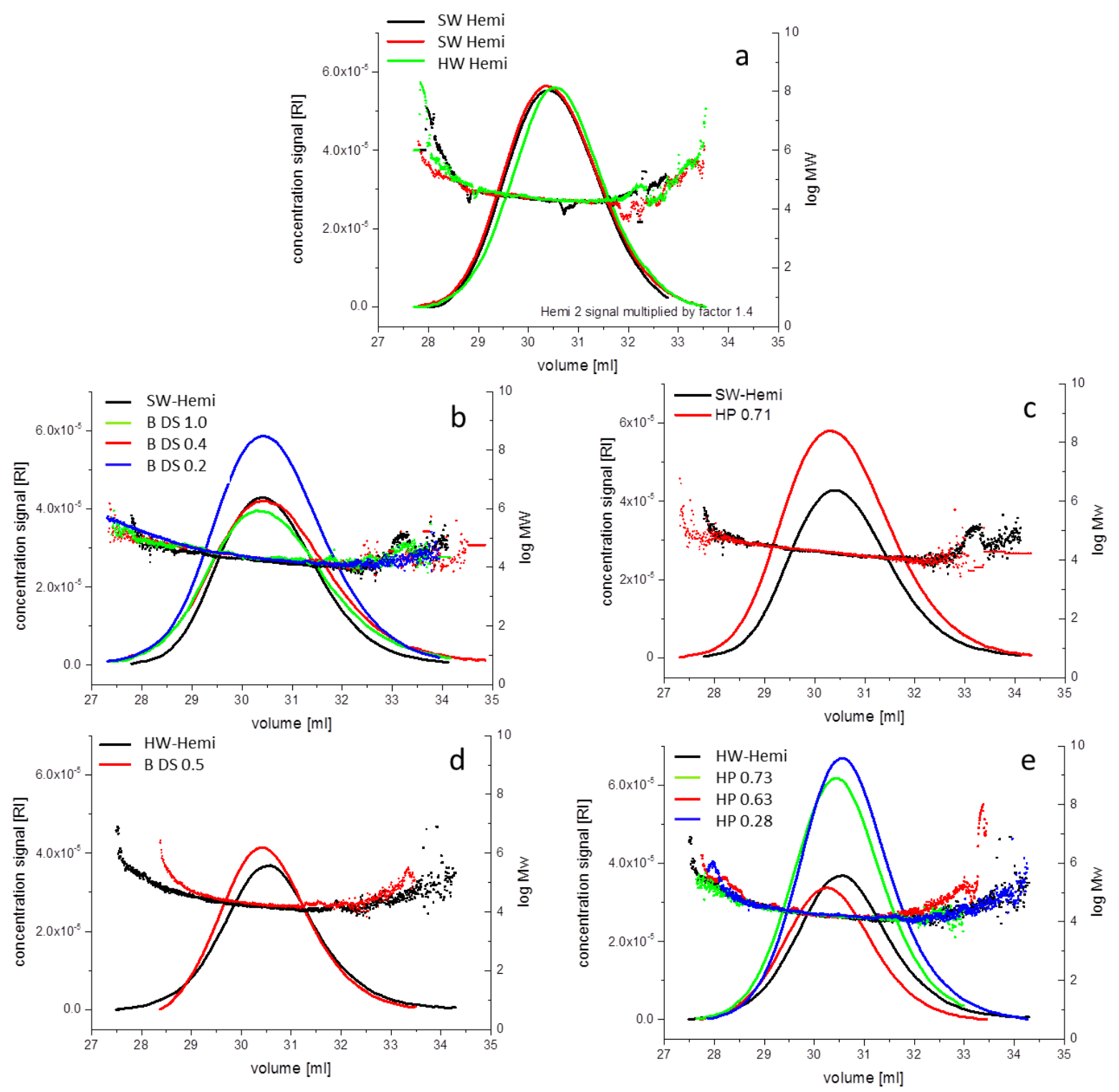

Figure S4. GPC elution profiles of the analysis of the softwood and hardwood hemicelluloses (a) used as starting materials for butylated (a) and hydroxypropylated (b) softwood hemicelluloses, and butylated (c) and hydroxypropylated (d) hardwood hemicelluloses. 
Table S1. Weight averaged molar mass $\left(\mathrm{M}_{\mathrm{w}}\right)$ of the hemicellulose raw materials and the hydroxypropylated and butylated derivatives.

\begin{tabular}{|c|c|c|c|c|c|c|}
\hline \multicolumn{7}{|c|}{ Raw materials } \\
\hline Source & \multicolumn{3}{|c|}{$\mathrm{M}_{\mathrm{w}}\left(\mathrm{g} \mathrm{mol}^{-1}\right)$} & \multicolumn{3}{|c|}{ Std. Dev } \\
\hline SW & \multicolumn{3}{|c|}{19510} & \multicolumn{3}{|c|}{2327} \\
\hline HW & \multicolumn{3}{|l|}{18100} & \multicolumn{3}{|l|}{6435} \\
\hline & \multicolumn{3}{|c|}{ Hydroxypropylated } & \multicolumn{3}{|c|}{ Butylated } \\
\hline Source & DS & $\mathrm{M}_{\mathrm{w}}\left(\mathrm{g} \mathrm{mol}^{-1}\right)$ & Std.Dev. & DS & $\mathrm{M}_{\mathrm{w}}\left(\mathrm{g} \mathrm{mol}^{-1}\right)$ & Std.Dev. \\
\hline SW & HP 0.71 & 19340 & 1584 & B 0.2 & 23195 & 1648 \\
\hline SW & & & & В 0.4 & 21020 & 1245 \\
\hline SW & & & & B 1.0 & 21900 & 481 \\
\hline HW & HP 0.73 & 16270 & 42 & В 0.5 & 17143 & 1093 \\
\hline HW & HP 0.63 & 17985 & 700 & & & \\
\hline HW & HP 0.62 & 17815 & 361 & & & \\
\hline HW & HP 0.28 & 17215 & 1011 & & & \\
\hline
\end{tabular}

SW= softwood, HW= hardwood

\section{Contact angle measurements on the hemicellulose ether films on a glass support}

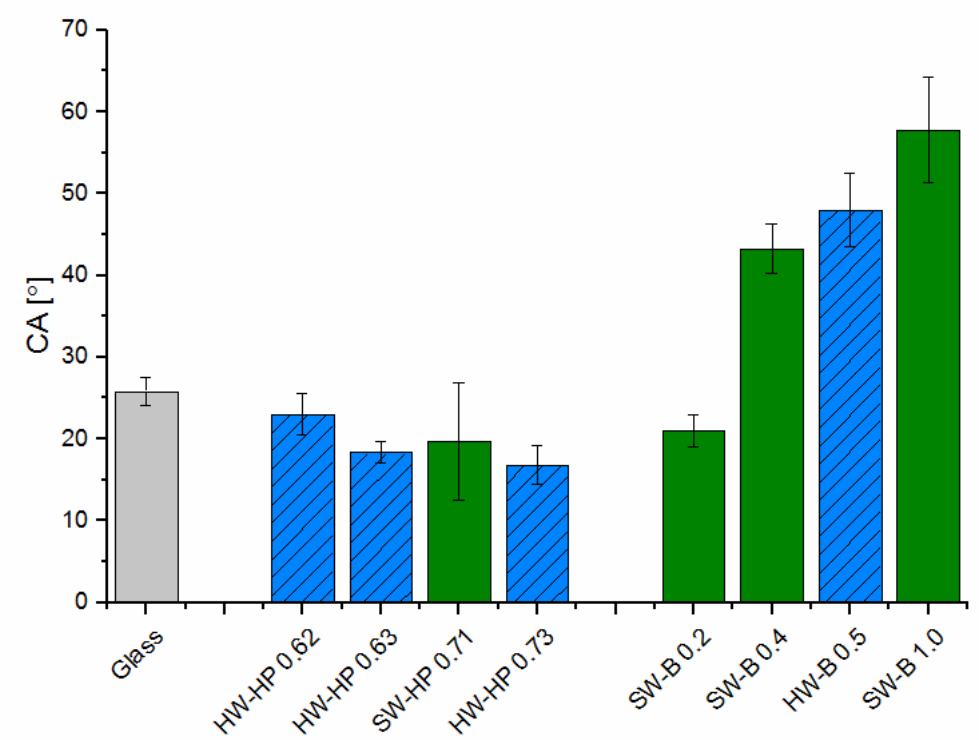

Figure S5. Water contact angle measurements of hemicelluloses spin coated on a glass plate. The bars denoting the softwood grades are with green solid color and the hardwood grades in blue diagonal texture. 